\title{
The Regulation of Diaminopimelate Decarboxylase Activity in Escherichia coli strain w
}

\author{
By P. J. WHITE \\ Department of Microbiology, The University, Sheffield SIO $2 T N$
}

(Received I8 December I975; revised I4 April I976)

\begin{abstract}
SUMMARY
Activity of diaminopimelate decarboxylase in Escherichia coli strain w, growing in an aerated fermenter, was only slightly ( $14 \%$ ) repressed by 2 mM-lysine when approximately equimolar diaminopimelate was present in the medium. Lysine alone caused $78 \%$ repression. Diaminopimelate did not interfere with uptake of lysine by growing organisms. Organisms grown in medium containing diaminopimelate, without lysine, had a decarboxylase activity $24 \%$ higher than organisms from minimal medium. The extent of repression by pyridoxine $(56 \%$ when added to minimal medium) was decreased (to $3 \mathrm{I} \%$ ) when diaminopimelate was also present in the medium. A diaminopimelate-requiring mutant, with limited ability to take up diaminopimelate, formed almost three times less diaminopimelate decarboxylase than did a diaminopimelate-requiring second-stage mutant that had an increased rate of transport of this amino acid. The internal concentration of diaminopimelate thus probably regulates the activity of the decarboxylase by induction. Lysine might not directly repress the enzyme but might give an apparent repression by restricting the biosynthesis of diaminopimelate. This restriction is probably not caused only by inhibition or repression of aspartokinase. Lysine and threonine together, though not singly, almost completely inhibited aspartokinase in vitro but caused less apparent repression of diaminopimelate decarboxylase than did lysine alone. Lysine plus diaminopimelate strongly repressed the lysine-sensitive aspartokinase $(85 \%)$ without much affecting diaminopimelate decarboxylase formation, and pyridoxine repressed the decarboxylase without affecting aspartokinase.
\end{abstract}

\section{INTRODUCTION}

Diaminopimelate decarboxylase (EC. 4.I.I.20; meso-2,6-diaminopimelate carboxy-lyase) catalyses the removal of carbon dioxide from meso-diaminopimelate to yield L-lysine (Work, I962). Pyridoxal phosphate is required as cofactor (White \& Kelly, I965). Enzyme activity in most bacteria is lower when lysine is added to chemically defined media (Denman, Hoare \& Work, I955; Patte, Loviny \& Cohen, 1962 ; White et al., I964; Gilboe, Friede \& Henderson, I968; Grandgenett \& Stahly, I97I). Adding diaminopimelate to minimal media does not significantly alter enzymicactivity (White et al., 1964). Hence, diaminopimelate decarboxylase was thought not to be induced by its substrate, but to be repressed by lysine, the end-product of its action. Lysine can also inhibit diaminopimelate decarboxylase action (White \& Kelly, I965; Rosner, 1975). In wild-type Escherichia coli strain w and in some mutants of this and of other strains of $E$. coli, the activity of diaminopimelate decarboxylase is also decreased when pyridoxine is present in the growth medium (Denman et al., 1955; White et al., 1964; Bukhari \& Taylor, 197I).

The findings reported in this paper suggest that in $E$. coli w the enzymic activity is really controlled by the internal concentration of diaminopimelate, and that the effects of both 
lysine and pyridoxine arise by changing the internal concentration of diaminopimelate. A preliminary report of this work has already been made (White, 1974).

\section{METHODS}

Organisms. Escherichia coli w (ATCC9637) was maintained as described previously (White \& Kelly, I965). Mutant I73-25 (Davis, 1952) is derived from strain w, and requires diaminopimelate plus lysine for rapid growth on a minimal medium, though the mutant will grow slowly in medium supplemented only with diaminopimelate. Mutant D3 was obtained by serial transfers of mutant $173-25$ in medium containing diaminopimelate plus decreasing concentrations of lysine, as described by Meadow, Hoare \& Work (1957), until organisms were obtained that grew in medium supplemented only with diaminopimelate as rapidly as the wild type grew in minimal medium. The similar mutants D (Meadow et al., I957) and D2 (Leive \& Davis, 1965) were no longer available. Mutant 173-25 was maintained in the same way as the parent strain, but on slopes of nutrient agar plus diaminopimelate (I00 $\mathrm{m}^{-1}$ ); minimal medium plus diaminopimelate (I00 $\mathrm{mg}^{-1}$ ) was used to maintain mutant D3.

Medium. The minimal medium of Davis \& Mingioli (1950) was used with $0.2 \%$ glucose (autoclaved separately). Additions to the medium are given in Results.

Growth of cultures. Organisms were grown in shaken 21 flasks containing $250 \mathrm{ml}$ medium, as described previously (White \& Kelly, 1965). Larger cultures (II l) were grown in a Microferm Laboratory Fermenter (New Brunswick Scientific Co., New Brunswick, New Jersey, U.S.A.) at $37^{\circ} \mathrm{C}$ with an airflow of $21 \mathrm{~min}^{-1}$; no antifoam agent was added. The inoculum for the fermenter was approx. $2 \times 10^{8}$ organisms from a fresh slope culture; the organisms were suspended in water and added to the warmed medium. Turbidity became visible in the culture after incubation for about $\mathrm{I} 6 \mathrm{~h}$ except when mutant $173-25$ was grown without lysine; in this case there was a lag of $24 \mathrm{~h}$ before turbidity was visible.

Assay of diaminopimelate decarboxylase. Organisms were harvested and washed, extracts were prepared and enzymic activity was measured manometrically under $\mathrm{N}_{2}$ as described by White (I97I). No correction was made for retention of $\mathrm{CO}_{2}$ by the buffer (pH 6.8) and all enzymic activities are expressed as manometric units (White \& Kelly, 1965).

Assay of lysine decarboxylase. Extracts (about $3 \mathrm{mg}$ protein) plus pyridoxal phosphate $(\mathrm{I} 00 \mu \mathrm{g}$ ) and 2-mercaptopropan-I-ol (final concentration I $\mathrm{mM}$ ) were incubated in 0.05 M-phosphate buffer $\mathrm{pH} 6 \cdot 0$ or $6.8(2 \cdot 5 \mathrm{ml})$. Release of $\mathrm{CO}_{2}$ from L-lysine $(2 \mathrm{mg})$ was measured manometrically in $\mathrm{N}_{2}$ at $37^{\circ} \mathrm{C}$ in a Warburg apparatus. One unit of lysine decarboxylase was the amount of enzyme that liberated I $\mu \mathrm{mol} \mathrm{CO}_{2}$ in I min at $\mathrm{pH} 6.0$.

Assay of aspartokinase. The method of Black \& Wright (1955) as described by TruffaBachi \& Cohen (I970) was used, but with the $\mathrm{FeCl}_{3} \cdot 6 \mathrm{H}_{2} \mathrm{O}$ dissolved in $\mathrm{I} \mathrm{M}-\mathrm{HCl}$. Samples were assayed for product formed after $0,10,20$ and $30 \mathrm{~min}$, and the rate of reaction was determined graphically. One unit of aspartokinase was the amount of enzyme that formed I $\mu \mathrm{mol}$ aspartic acid $\beta$-hydroxamate in I min.

Estimations. Diaminopimelate was assayed by the acidic ninhydrin method at $37^{\circ} \mathrm{C}$ (Work, 1957), in which lysine does not interfere.

Lysine was assayed (in the presence of diaminopimelate) by the method of Shimura \& Vogel (I966).

Protein was assayed by the method of Lowry et al. (195I) with crystalline bovine serum albumin as standard.

Dry weight of bacterial suspensions was determined as described by White \& Kelly (I965). 
Growth was measured turbidimetrically with an EEL colorimeter as described by White et al. (I964). A colorimeter reading of $\mathrm{I} \cdot 0$ corresponded to $0.3 \mathrm{mg}$ dry wt organisms $\mathrm{ml}^{-1}$ and to $\mathrm{I} \times 1 \mathrm{O}^{9}$ organisms $\mathrm{ml}^{-1}$.

Uptake of $\left[\mathrm{I}^{14} \mathrm{C}\right]$ diaminopimelic acid. The procedure was based on the method of Leive \& Davis (1965). Organisms were harvested in the exponential phase of growth and washed once in minimal medium without glucose and ammonium salts (solution D). The washed bacteria were suspended in minimal medium with glucose but without ammonium salts, to a density of $0.2 \mathrm{mg}$ dry $\mathrm{wt} \mathrm{ml}^{-1}$. This suspension ( $\mathrm{IO} \mathrm{ml}$ ) was equilibrated at $37^{\circ} \mathrm{C}$ in a test-tube, and at zero time $0.2 \mathrm{ml}\left[{ }^{1-14} \mathrm{C}\right]$ diaminopimelate $\left(75 \mathrm{nmol} ; 2.3 \times 10^{4}\right.$ c.p.m. $)$ in solution D was added. Samples $(2 \mathrm{ml}$ at zero time and $5 \mathrm{~min}$, and thereafter $\mathrm{I} \mathrm{ml}$ ) were removed, quickly added to $2 \mathrm{ml} 0.2 \mathrm{~mm}$-meso-diaminopimelate at $0{ }^{\circ} \mathrm{C}$ in solution $\mathrm{D}$, and rapidly filtered through Millipore type HA membranes ( $25 \mathrm{~mm}$ diam., $0.45 \mu \mathrm{m}$ porosity, presoaked in $0.2 \mathrm{mM}$-meso-diaminopimelate in solution D). The discs and collected organisms were washed once at room temperature with $3 \mathrm{ml} 0.2 \mathrm{mM}$-meso-diaminopimelate in solution $\mathrm{D}$ and then transferred to Io $\mathrm{ml}$ scintillation fluid (Bray, r960) in glass vials. The vials were shaken until the membranes had dissolved and then radioactivity was measured by scintillation counting. Corrections for varying efficiencies of counting were made with a quench calibration curve.

Chemicals. Unless stated otherwise, diaminopimelic acid was a mixture of about $80 \%$ meso- and $20 \%$ LL-isomers, and was kindly given by Chas. Pfizer \& Co., Groton, Connecticut, U.S.A. From it, meso- and LL-diaminopimelate were isolated as described by White, Lejeune \& Work (1969). DD-Diaminopimelate was isolated from synthetic diaminopimelic acid as described by Saleh \& White (I975). $\left[\mathrm{I}-{ }^{14} \mathrm{C}\right]$ Diaminopimelate was purchased from Calatomic, 54984 Terminal Annex, Los Angeles, California, U.S.A. 3-Hydroxy-2,6-diaminopimelic acid (racemic isomer B; Stewart, 196r) was a gift from Dr C. Gilvarg (Princeton University, U.S.A.); in this isomer the amino groups are in the meso-configuration.

\section{RESULTS}

All of the enzymic activity measured after the organisms had been made permeable to external diaminopimelate by detergent treatment (White et al., 1964) was easily and reproducibly obtained in a soluble extract prepared with a French pressure cell (Milner, Lawrence \& French, 1950) and a motor-driven hydraulic press (American Instruments, Silver Spring, Maryland, U.S.A.).

\section{Effects of lysine, diaminopimelate and pyridoxine on diaminopimelate decarboxylase activities}

Lysine. Diaminopimelate decarboxylase activity in exponential-phase organisms decreased when L-lysine was added to the medium (Fig. I). The maximum apparent repression (about $60 \%$ ) was at $40 \mathrm{mg}^{-1}$. Although higher concentrations of lysine had no greater effect (White et al., 1964), the internal concentration of lysine had not presumably reached its highest possible level because lysine decarboxylase was only found in organisms when lysine in the medium was at $100 \mathrm{mg} \mathrm{1}^{-1}$ or higher (White et al., I964). D-Lysine (up to $100 \mathrm{mg}^{-1}$ ) caused no repression of diaminopimelate decarboxylase; with $\mathrm{D}$-lysine at $40 \mathrm{mg}^{-1}$, enzymic activity was about $25 \%$ higher than in minimal medium. Stimulation by D-lysine has been noticed previously (White et al., 1964), but has not been thoroughly studied.

Decarboxylation of 4 mM-meso-diaminopimelate was inhibited by $34 \%$ when $40 \mathrm{~mm}$ L-lysine was added to the assay system with an extract of organisms from minimal medium. 


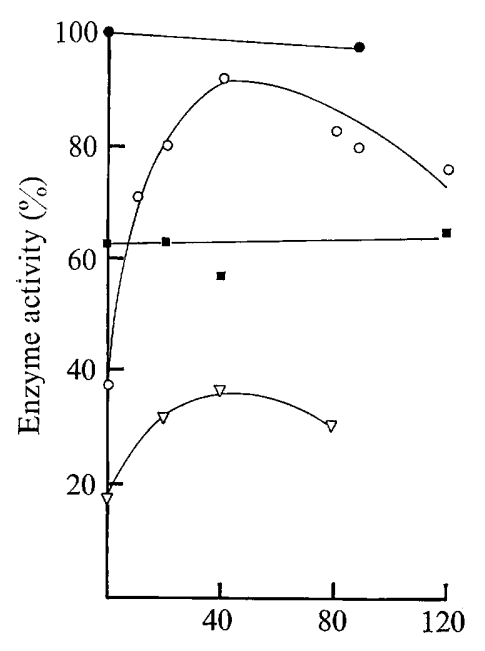

Diaminopimelate concn $\left(\mathrm{mg} \mathrm{l}^{-1}\right)$

Fig. 1

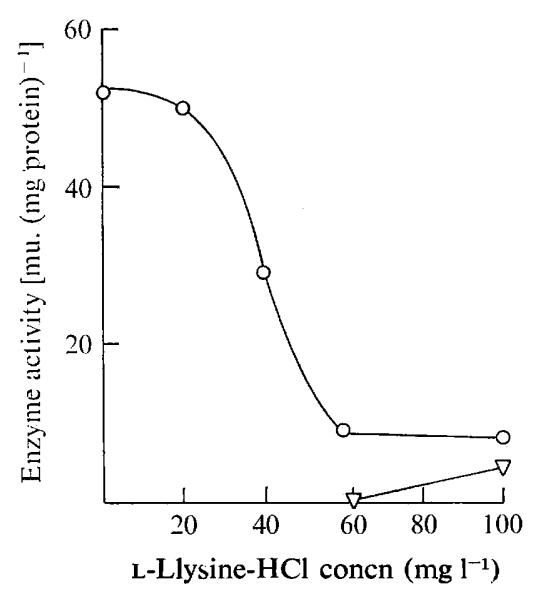

Fig. 2

Fig. I. Activity of diaminopimelate decarboxylase in extracts of E. coli w grown with various concentrations of diaminopimelic acid in : $\mathbf{0}$, minimal medium; $\mathbf{\square}$, medium plus pyridoxine (Io mg $\left.1^{-1}\right) ; \bigcirc$, medium plus L-lysine $\left(40 \mathrm{mg} \mathrm{l}^{-1}\right) ; \nabla$, medium plus lysine and pyridoxine. Organisms were grown in shaken flasks and harvested in the mid-exponential phase of growth when the colorimeter reading was about $\mathrm{I} \cdot 0$. Diaminopimelate decarboxylase activities are expressed as a percentage of the activity in minimal medium.

Fig. 2. Activity of diaminopimelate decarboxylase $(\bigcirc)$ and lysine decarboxylase $(\nabla)$ in extracts of $E$. coli $\mathrm{w}$ grown in minimal medium plus pyridoxine (Io $\mu \mathrm{g} \mathrm{ml}^{-1}$ ) and various concentrations of lysine. Organisms were grown as described in Fig. I. Lysine decarboxylase was measured at $\mathrm{pH}$ $6 \cdot 0$; its activity was lower at $\mathrm{pH} 6 \cdot 8$.

Added 40 mm-lysine inhibited diaminopimelate decarboxylase by $38 \%$ when the extract was from organisms grown with L-lysine $\left(40 \mathrm{mg} \mathrm{1}^{-1}\right)$.

Lysine plus diaminopimelate. Adding diaminopimelate to the minimal medium had only a slight effect on the diaminopimelate decarboxylase activity (Fig. I). However, when lysine ( $40 \mathrm{mg}^{-1}$ ) was in the medium, adding diaminopimelate from o to $40 \mathrm{mg}^{-1}$ progressively restored enzymic activity almost to the level found in organisms grown without lysine. This increase of activity was not due to the formation of lysine decarboxylase, which would, if it were present as well as diaminopimelate decarboxylase, increase the measured rate of $\mathrm{CO}_{2}$ evolution from diaminopimelate. No lysine decarboxylase was found at $\mathrm{pH} 6 \cdot 0$ (optimal for this enzyme) or at $\mathrm{pH} 6.8$ (at which diaminopimelate decarboxylase activity is optimal and is assayed) in extracts of organisms grown with lysine $\left(40 \mathrm{mg}^{-1}\right)$ plus diaminopimelate (40 $\mathrm{mg} \mathrm{1}^{-1}$ ).

Either pure meso- or pure LL-diaminopimelate gave results similar to those described above for the mixed isomers. These two isomers are interconvertible by the enzyme diaminopimelate epimerase, which is present in E. coli (Antia, Hoare \& Work, 1957). DD-Diaminopimelate is neither a substrate nor an inhibitor of the epimerase or decarboxylase. Growth of $E$. coli $\mathrm{w}$ in shaken flasks with DD-diaminopimelate completely prevented repression of diaminopimelate decarboxylase by lysine, but the enzyme was not induced by the DD-isomer (Table I).

3-Hydroxy-2,6-diaminopimelate also was neither a substrate nor an inhibitor of diaminopimelate decarboxylase. This compound completely prevented repression of the 
Table I. Activity of diaminopimelate decarboxylase in extracts of E. coli strains $\mathrm{w}, \mathrm{I} 73-25$ and $\mathrm{D} 3$ after growth with various additions to the medium

Organisms were grown in minimal medium with various additions, in shaken flasks or in an aerated fermenter (see Methods). Flask cultures were harvested when the colorimeter reading (turbidity) was about $\mathrm{I} \cdot \mathrm{O}$ and extracts were made from the washed organisms. Fermenter cultures were sampled at intervals and the enzymic activities were determined from differential plots (see Fig. 3). Results are for $E$. coli w, except where indicated. Unless stated otherwise, diaminopimelate was a mixture of meso- and LL-isomers, and other amino acids were L-isomers. The additions were used throughout at the concentrations given at first mention in the Table.

\begin{tabular}{|c|c|c|c|}
\hline \multicolumn{4}{|c|}{$\begin{array}{l}\text { Diaminopimelate decarboxylase activities } \\
\left.\left[(\mathrm{nmol} \mathrm{CO})_{2}\right) \min ^{-1}(\mathrm{mg} \text { protein })^{-1}\right]\end{array}$} \\
\hline \multicolumn{2}{|c|}{ Flask cultures } & \multicolumn{2}{|c|}{ Fermenter cultures } \\
\hline $\begin{array}{l}\text { No pyridoxine } \\
\text { in medium }\end{array}$ & $\begin{array}{l}\text { Pyridoxine } \\
\left(10 \mathrm{mg} \mathrm{l}^{-1}\right) \\
\text { in medium }\end{array}$ & $\begin{array}{l}\text { No pyridoxine } \\
\text { in medium }\end{array}$ & $\begin{array}{l}\text { Pyridoxine } \\
\left(10 \mathrm{mg} \mathrm{l}^{-1}\right) \\
\text { in medium }\end{array}$ \\
\hline 80 to 100 & 59 & 114 & 50 \\
\hline 32 & 14 & 25 & 13 \\
\hline 105 & ND & ND & ND \\
\hline 90 & 58 & $\begin{array}{l}\text { I4 I } \\
\text { I } 2 * \\
29 \dagger\end{array}$ & 79 \\
\hline 86 & ND & ND & ND \\
\hline 85 & ND & ND & ND \\
\hline 102 & ND & ND & ND \\
\hline 119 & ND & ND & ND \\
\hline $8 \mathrm{I}$ & 32 & 98 & 32 \\
\hline 104 & ND & ND & ND \\
\hline 86 & ND & ND & ND \\
\hline 36 & ND & 50 & ND \\
\hline 90 & ND & I I 4 & ND \\
\hline $3 I$ & 13 & ND & ND \\
\hline $\begin{array}{l}\text { ND, Not detern } \\
* \text { Mutant I73- } \\
\dagger \text { Mutant D3. }\end{array}$ & & & \\
\hline
\end{tabular}

decarboxylase by lysine, and also caused a slight induction of the enzyme when added to minimal medium in shaken flasks (Table I). Insufficient DD- or 3-hydroxydiaminopimelate was available to allow experiments with these compounds in fermenter-grown cultures.

Pyridoxine. Previous studies (White et al., 1964) showed that adding pyridoxine to minimal medium decreased diaminopimelate decarboxylase activity in detergent-treated $E$. coli w, and this effect was distinct from the effect of lysine on the enzyme. Activities of diaminopimelate decarboxylase in soluble extracts are also decreased by pyridoxine in the growth medium. Enzymic activity of organisms grown in shaken flasks with pyridoxine was not increased by adding diaminopimelate to the medium, though the activity of the enzyme in organisms grown with pyridoxine plus lysine was raised by adding diaminopimelate (Fig. I). When pyridoxine was in the growth medium, the maximum repression of diaminopimelate decarboxylase was reached with lysine at $50 \mathrm{mg}^{-1}$. Lysine decarboxylase began to be induced only when lysine was at $80 \mathrm{mg}^{-1}$ (Fig. 2). Thus the effect of pyridoxine is probably not a consequence of raising the concentration of lysine in the bacteria.

All the experiments so far described were done with exponential-phase cultures grown in shaken flasks; in these, diaminopimelate decarboxylase activity varies with the stage of 


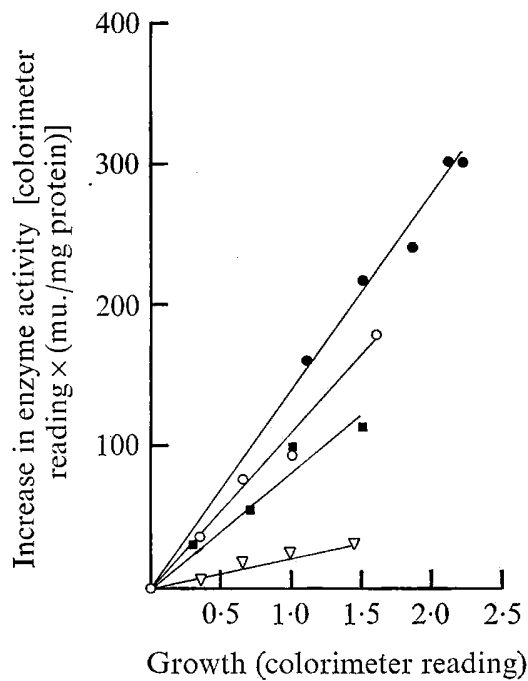

Fig. 3

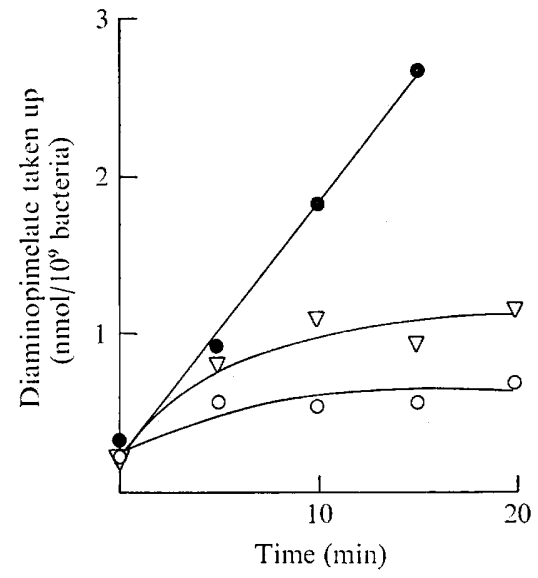

Fig. 4

Fig. 3. Differential plots of diaminopimelate decarboxylase activities in fermenter-grown cultures of E. coli $\mathrm{w}$ in: $\mathrm{O}$, minimal medium;, medium plus diaminopimelate $\left(44 \mathrm{mg} \mathrm{l}^{-1}\right) ; \nabla$, medium plus L-lysine $\left(40 \mathrm{mg} \mathrm{l}^{-1}\right) ; \mathbf{n}$, medium plus lysine and diaminopimelate. Samples (I to 21 culture) were taken, turbidities were measured and extracts were prepared from the washed organisms.

Fig. 4. Uptake of $\left[\mathrm{I}^{14} \mathrm{C}\right]$ diaminopimelic acid by suspensions of $E$. coli : $O$, strain $\mathrm{w} ; \nabla$, strain 173-25;0, strain D3. Procedure was as described in Methods.

growth (White et al., 1964). When organisms were grown in an II 1 fermenter, the rates of enzyme synthesis with various additions to the medium could be compared by 'differential plots' (Monod, Pappenheimer \& Cohen-Bazire, 1952) of the amount of enzyme in the culture $[(\mathrm{mu} . / \mathrm{mg}$ protein $) \times$ turbidity $]$ against the weight of bacteria in the culture (turbidity) at the time of sampling (Fig. 3).

The fermenter cultures showed some differences in diaminopimelate decarboxylase activities from those grown as flask cultures in media of the same composition. In the fermenter, enzyme was formed at a constant differential rate throughout growth; enzymic activity in minimal medium was higher; the depressing effects of lysine and pyridoxine on enzyme synthesis were more marked; diaminopimelate more effectively prevented these effects of both lysine and pyridoxine; and adding diaminopimelate to the minimal medium stimulated enzymic activity (Table I).

\section{Activity of diaminopimelate decarboxylase in the diaminopimelate-requiring mutants} 173-25 and $\mathrm{D} 3$, and the uptake of diaminopimelate by these mutants and the wild type

Leive \& Davis (1965) isolated from strain I73-25 a second-stage mutant (called D2) that grew quickly in minimal medium supplemented with diaminopimelate alone, and they showed that $\mathrm{D} 2$ organisms seemed to differ from $\mathbf{1} 73-25$ only by this growth response and by taking up $\left[{ }^{14} \mathrm{C}\right]$ diaminopimelate more rapidly.

The uptake of $\left[{ }^{14} \mathrm{C}\right]$ diaminopimelate by washed suspensions of strains $\mathrm{W}, \mathrm{I} 73-25$ and $\mathrm{D} 3$ were compared (Fig. 4). The D3 organisms took up diaminopimelate faster and to a greater extent than did strains $W$ or $173-25$ under the conditions of Leive \& Davis (1965). The 


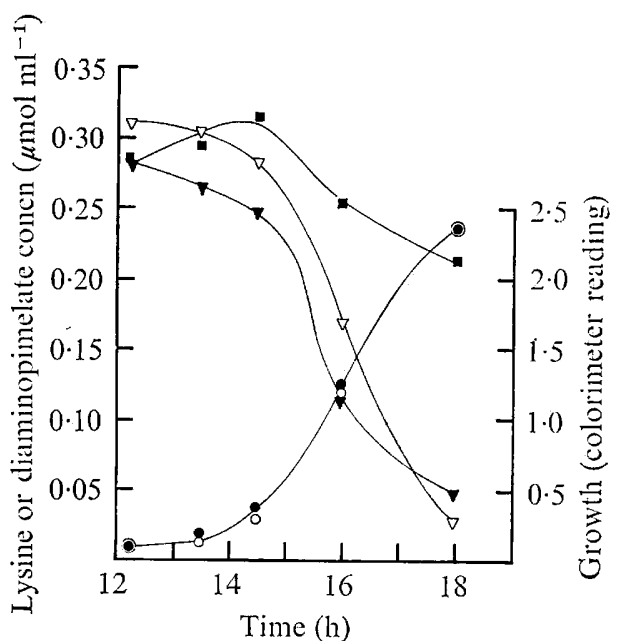

Fig. 5

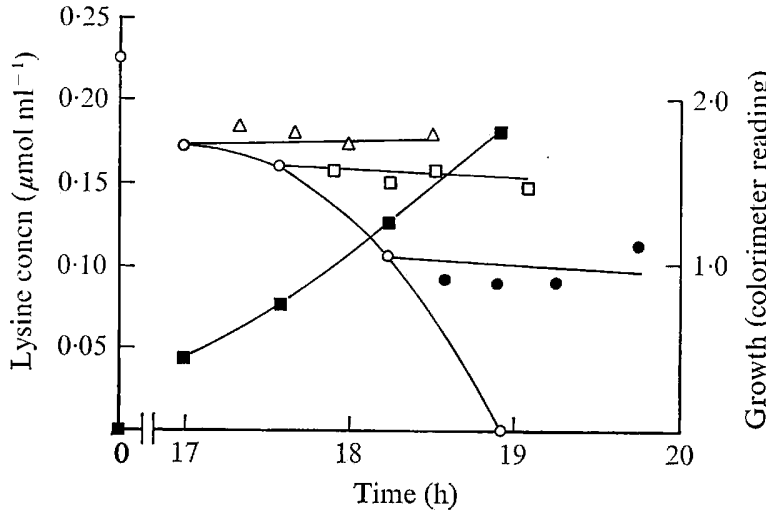

Fig. 6

Fig. 5. Disappearance of lysine and diaminopimelate during growth of $E$. coli w. Organisms were grown in shaken flasks at $37^{\circ} \mathrm{C}$ with L-lysine hydrochloride $\left(50 \mathrm{mg} \mathrm{l}^{-1}\right.$ ) or with lysine plus diaminopimelate $\left(50 \mathrm{mg}^{-1}\right)$ in minimal medium. Samples were taken, their turbidities were measured, and, after centrifuging, the supernatant liquids were assayed for lysine and diaminopimelate. $\bigcirc$, Growth in minimal medium plus lysine; $\boldsymbol{\theta}$, growth in minimal medium plus lysine and diaminopimelate; $\nabla$, lysine concentration (no diaminopimelate added) ; $\nabla$, lysine concentration (diaminopimelate added); $\mathbf{\square}$, diaminopimelate concentration. (A separate experiment, not illustrated, showed that the rates of disappearance of diaminopimelate and of growth were unaltered when only diaminopimelate was added to the minimal medium.)

Fig. 6. Persistence of lysine in culture filtrates of $E$. coli $\mathrm{w}$ after removing the bacteria. Organisms were grown with lysine, as described in Fig. 5. At intervals, samples were taken, and the organisms were removed by filtering. These sterilized solutions were incubated at $37^{\circ} \mathrm{C}$ and assayed at intervals for lysine. $\bigcirc$, Lysine concentration at time of sampling; $\Delta, \square$ and $\boldsymbol{\theta}$, lysine concentration in culture filtrates on continued incubation after removal of bacteria ; $\mathbf{\square}$, growth. [Similar results, not illustrated, were obtained when diaminopimelate $\left(50 \mathrm{mg} \mathrm{l}^{-1}\right)$ was present in the medium with lysine.]

conditions in a fermenter-grown culture were considerably different, and so it is possible that the rates of uptake of diaminopimelate by organisms in the fermenter were unlike the measured rates.

Both mutants (D3 and $173-25$ ) grew in the aerated fermenter in medium supplemented only with diaminopimelate $\left(44 \mathrm{mg}^{-1}\right)$ though $173^{-25}$ grew with a longer doubling time (I IO min) than D3 or the wild type (40 min). The differential rate of formation of diaminopimelate decarboxylase was $\mathbf{2 . 5}$ times higher in D3 than in $173-25$, although D3 itself only formed the enzyme at one quarter of the rate of the parent strain (Table I). Nevertheless, D3 does contain more than sufficient enzyme per $\mathrm{mg}$ protein to form lysine quickly enough to double its protein content (assuming one-twentieth of the protein is lysine) in $20 \mathrm{~min}$, which is a shorter period than the observed mean generation time. Adding lysine $\left(40 \mathrm{mg} \mathrm{l}^{-1}\right)$ as well as diaminopimelate had no effect on enzyme synthesis by either mutant.

When the rates of disappearance of lysine and diaminopimelate from the medium of growing cultures of E. coli w were compared (Fig. 5), disappearance of each amino acid was unaffected by the other. The disappearance of lysine must represent uptake, because no exoenzyme that degraded lysine was found in culture filtrates (Fig. 6). 
Table 2. Activity of aspartokinase in extracts of E. coli w after growth with various additions to the medium

\begin{abstract}
Organisms were grown in shaken flasks of minimal medium with various additions. Cultures were harvested in the mid-exponential phase of growth (colorimeter reading about $\mathrm{I} \cdot 0$ ) and extracts were made from the washed organisms. The isomeric compositions and concentrations of the additions (where not specified) were as given in Table I. Enzyme activities are expressed as a percentage of the activity in minimal medium.
\end{abstract}

\begin{tabular}{lcc}
\multicolumn{2}{c}{ Eddition } & \multicolumn{2}{c}{ Enzyme activities (\%) } \\
\cline { 2 - 3 } None & Aspartokinase & Diaminopimelate decarboxylase \\
Lysine & $100^{*}$ & $100 \dagger$ \\
Diaminopimelate & $54 \ddagger$ & 35 \\
Lysine plus diaminopimelate & 100 & 100 \\
Pyridoxine & $58 \S$ & 90 \\
Threonine & 100 & 65 \\
Lysine plus threonine & 92 & ND \\
Phenylalanine & 38 & 40 \\
L-Tryptophan (40 mg 1-1) & 100 & 100 \\
Lysine plus phenylalanine & 100 & 100 \\
Pyridoxine plus diaminopimelate & 39 & 35 \\
& 100 & 65
\end{tabular}

ND, Not determined.

* About 80 mu. (mg protein $)^{-1}$.
+ About $90 \mathrm{mu}$. (mg protein) $)^{-1}$.
$\$ 50 \%$ when I mM-lysine added to assay system.
$\S 5 \mathrm{I} \%$ when I mM-lysine added to assay system.

Activity of aspartokinase in E. coli $\mathrm{w}$

Lysine and other amino acids have differing complex regulatory effects on aspartokinase activity in various strains of E. coli (see review by Umbarger, 1969). Patte, Loviny \& Cohen (1965) reported that phenylalanine enhanced the inhibitory effect of lysine on the lysinesensitive aspartokinase of $E$. coli, and this might explain the slight repression of diaminopimelate decarboxylase by phenylalanine found by White et al. (1964). Decrease in the activity of aspartokinase might possibly lower the internal concentration of diaminopimelate, which might in turn then induce less decarboxylase. However, unless aspartokinase is totally inhibited in vivo, decreased activity of this enzyme will not necessarily lead to a decreased flow of carbon to diaminopimelate. Lysine also represses aspartic semialdehyde dehydrogenase (Cohen \& Patte, 1963) and inhibits the condensation reaction between aspartic semialdehyde and pyruvate (Yugari \& Gilvarg, 1962).

The activities of aspartokinase and diaminopimelate decarboxylase were compared in extracts of $E$. coli $\mathrm{w}$ that had been grown with various additions to the medium (Table 2). Phenylalanine added alone to the medium did not affect either enzyme, even when organisms were used from freeze-dried material that had been preserved at the time (I962) when the repression by phenylalanine was first noticed; tryptophan was also ineffective. Phenylalanine slightly increased the repression of aspartokinase by lysine and partly inhibited this enzyme as well (Table 3). Threonine alone was not inhibitory, but threonine plus lysine caused almost tota? inhibition of aspartokinase in vitro. Nevertheless, when these two amino acids were added to the minimal medium, they caused little more repression of aspartokinase than did lysine alone, and did not prevent formation of diaminopimelate decarboxylase. The flow of carbon to diaminopimelate may therefore be chiefly controlled at the condensation of aspartic semialdehyde with pyruvate, and at aspartic semialdehyde dehydrogenase. 
Table 3. Activity of aspartokinase in an extract of $E$. coli $\mathrm{w}$ with various additions to the assay system

\begin{abstract}
Additions to the assay system were made with an extract of organisms grown in minimal medium [uninhibited aspartokinase activity $80 \mathrm{mu}$. (mg protein) ${ }^{-1}$ ]. The isomers of the amino acids (where not specified) were as given in Tables I and 2. Aspartokinase activity is expressed as a percentage of the activity measured when no additions were made to the assay system.
\end{abstract}

Addition

None

Lysine (I mM)

Diaminopimelate (Io $\mathrm{mm}$ )

Lysine plus diaminopimelate

Threonine (Io mM)

Lysine plus threonine

Phenylalanine (IO mM)

Tryptophan (Io mM)

L-Tyrosine (Io mM)

Lysine plus phenylalanine

Aspartokinase $(\%)$
100
$54^{*}$
100
60
100
15
62
100
59
39

* No greater inhibition with concentrations of lysine up to Io mM.

Lysine partly repressed aspartokinase in $E$. coli w and partly inhibited this enzyme in extracts of organisms grown in minimal medium. The residual aspartokinase activity of organisms grown with lysine was not inhibited by lysine. Thus, the lysine-sensitive enzyme is the one that is repressed by lysine. Patte, Boy \& Borne (I974) suggested that in E. coli KI 2 the synthesis of diaminopimelate decarboxylase was regulated by the activity of the lysinesensitive aspartokinase. This is clearly not the case in the present study: lysine plus diaminopimelate almost completely repressed the lysine-sensitive aspartokinase, but had very little effect on diaminopimelate decarboxylase; pyridoxine repressed the decarboxylase, but had no effect on aspartokinase. The experiments of Patte et al. (I974) are consistent with the view that a lowered aspartokinase activity may decrease the internal concentration of diaminopimelate and hence diminish synthesis of diaminopimelate decarboxylase. However, a difficulty in making comparisons is that Patte et al. (1974) used E. coli KI2 and found very much lower diaminopimelate decarboxylase activities [only $5 \mathrm{mu}$. (mg protein $)^{-1}$ in unrepressed bacteria] than are present in E. coli w.

\title{
DISCUSSION
}

Growth of $E$. coli w in the presence of lysine decreases the activity of diaminopimelate decarboxylase found in extracts, but this effect of lysine is almost completely overcome if diaminopimelate is also present in the medium. None of the other common natural amino acids abolished lysine repression of this enzyme (White et al., I964). Diaminopimelate does not stop the uptake of lysine (Fig. 5) and must, therefore, be able to overcome the apparent lysine repression at some internal site(s). Three interpretations seem possible :

(i) Lysine regulates diaminopimelate decarboxylase activity by inhibition (White \& Kelly, 1965; Rosner, 1975) rather than by repression of enzyme synthesis, and diaminopimelate might overcome or prevent the inhibition. This hypothesis is improbable because the dilution of the bacterial cytoplasm during extraction of the enzyme should decrease the concentration of lysine to a subinhibitory level (unless the lysine were very firmly bound to the diaminopimelate decarboxylase). Furthermore, the repressed decarboxylase from lysine-grown 
organisms was just as sensitive to inhibition by lysine as was the enzyme from organisms grown in minimal medium.

(ii) Lysine decreases the rate of synthesis of diaminopimelate decarboxylase but diaminopimelic acid prevents this repression.

(iii) Diaminopimelate induces the formation of diaminopimelate decarboxylase. Lysine might cause an apparent repression by decreasing the internal concentration of diaminopimelate by inhibition and/or repression of enzymes in the pathway of diaminopimelate biosynthesis.

A firm choice cannot yet be made between these hypotheses. The third most easily accounts for the experimental findings reported in this paper and does not demand any novel competitive interaction with lysine such as the first or second hypothesis requires.

The regulatory effects of lysine must not stop diaminopimelate biosynthesis completely, otherwise lysine in the medium would prevent formation of peptidoglycan. In contrast, there is no obvious reason why lysine should not repress diaminopimelate decarboxylase completely (which it does not), if it had a direct controlling effect on synthesis of this enzyme.

Growth of several strains of $E$. coli and other bacteria in flasks of minimal media plus diaminopimelate did not increase formation of diaminopimelate decarboxylase (White et al., 1964). However, diaminopimelate can accelerate enzyme formation when $E$. coli grows in an aerated fermenter. Diaminopimelate also behaves like an inducer when it is added in gradually increasing concentrations to medium containing lysine. Probably the very slow rate of uptake of diaminopimelate by $E$. coli (Leive \& Davis, 1965) prevents the induction being more striking.

The diaminopimelate-requiring mutant $173-25$ grows only slowly in minimal medium supplemented with diaminopimelate, but grows as quickly as its parent strain (W) with lysine plus diaminopimelate. Only about one-twentieth as much diaminopimelate needs to be taken up when it is wanted solely for peptidoglycan synthesis and is not required as a precursor of lysine. Consequently, the low rate of entry of diaminopimelate limits the rate of growth of $173-25$ only when lysine is not provided. The very low activity of diaminopimelate decarboxylase in $173-25$ grown with only a diaminopimelate supplement is consistent with a low internal concentration of the presumed inducer. The lack of any repression by lysine (plus diaminopimelate) with $\mathrm{I} 73-25$ is also consistent with the effect of lysine in the wild type being due to partial inhibition of diaminopimelate biosynthesis. However, even in the wild type, the effect of lysine in the medium is only slight when diaminopimelate is present. Mutant D3 transports diaminopimelate quickly enough to grow with diaminopimelate (in the absence of lysine) as rapidly as the wild type. The activity of diaminopimelate decarboxylase in the mutant D3 was almost three times higher than in 173-25 though it was still only one-quarter of that of the wild type.

A possible explanation can now be advanced for the repression of diaminopimelate decarboxylase that is caused by pyridoxine. White \& Kelly (1965) showed in vitro, and Bukhari \& Taylor (197I) showed in vivo, that in $E$. coli $\mathrm{W}$ the attachment between the diaminopimelate decarboxylase apoenzyme and its cofactor, pyridoxal phosphate, is very weak. When organisms grow with pyridoxine, the internal concentration of pyridoxal phosphate might become sufficient to activate every molecule of diaminopimelate decarboxylase protein that is synthesized. The catalytic activity of the holoenzyme may regulate its own further production, by decreasing the internal concentration of diaminopimelate or, less probably, by increasing the internal concentration of lysine. When pyridoxal phosphate is not in excess, the organisms may produce a surplus of apoenzyme (which is measured 
during enzyme assay) before enough active holoenzyme accumulates and shuts off further synthesis of apoenzyme. In other words, the enzymic activity measured after growth with pyridoxine may be a better indication of the true activity of the intracellular enzyme.

Kelleher \& Heggeness (1976) showed, with mutants of $E$. coli KI2, that repression of diaminopimelate decarboxylase apparently by lysine was less effective when the organisms contained additional copies of the lys $A$ gene, which codes for diaminopimelate decarboxylase. The authors did not consider the possibility of induction by diaminopimelate but suggested that synthesis of this enzyme is regulated by lysine in combination with a small number of lysine-repressor molecules that are insufficient to repress additional copies of the structural gene. The findings of Kelleher \& Heggeness (1976) are in fact equally consistent with the hypothesis that diaminopimelate regulates synthesis of the enzyme by combining with active repressor molecules that are formed in limited numbers.

The results described in this paper can more readily be explained with the hypothesis that diaminopimelate decarboxylase is induced by its substrate, rather than directly repressed by its product. In general, biosynthetic enzymes are not controlled by induction (Sanwall, 1970), though all other bacterial amino-acid decarboxylases (which are catabolic) are inducible enzymes (Gale, 1946). Possibly diaminopimelate decarboxylase was originally evolved as the first step in diaminopimelate degradation by organisms that had already gained the ability to make diaminopimelate for wall synthesis but previously had required lysine for growth (see review by Vogel, Thompson \& Shockman, I970). The control mechanism of a catabolic enzyme might have been retained even though the prime function has become biosynthetic.

I am grateful to Dr C. Gilvarg and to Chas. Pfizer \& Co., for gifts of chemicals. Miss Lorna B. Young gave valuable technical assistance throughout this work. Mutant $173-25$ was kindly provided by Dr Pauline Meadow.

\section{REFERENCES}

Antia, M., Hoare, D. S. \& Work, E. (I957). The stereoisomers of $\alpha, \epsilon$-diaminopimelic acid. 3. Properties and distribution of diaminopimelic acid racemase, an enzyme causing interconversion of the LL and meso isomers. Biochemical Journal 65, 448-459.

BLACK, S. \& WRIGHT, N. G. (1955). $\beta$-Aspartokinase and $\beta$-aspartyl phosphate. Journal of Biological Chemistry 213, 27-38.

BraY, G. A. (1960). A simple efficient liquid scintillator for counting aqueous solutions in a liquid scintillation counter. Analytical Biochemistry r, 279-285.

BukHARI, A. J. \& TAYLOR, A. L. (I97I). Mutants of Escherichia coli with a growth requirement for either lysine or pyridoxine. Journal of Bacteriology 105, 988-998.

COHEN, G. N. \& PATTE, J.-C. (I963). Some aspects of the regulation of amino acid biosynthesis in a branched pathway. Cold Spring Harbor Symposia on Quantitative Biology 28, 513-5I6.

DAVIS, B. D. (1952). Diaminopimelic acid and lysine. Biosynthetic interrelations of lysine, diaminopimelic acid, and threonine in mutants of Escherichia coli. Nature, London 169, 534-536.

Davis, B. D. \& Mingioli, E. S. (1950). Mutants of Escherichia coli requiring methionine or vitamin $\mathbf{B}_{12}$. Journal of Bacteriology 6o, I7-28.

Denman, R. F., Hoare, D. S. \& Work, E. (I955). Diaminopimelic acid decarboxylase in pyridoxin-deficient Escherichia coli. Biochimica et biophysica acta $\mathbf{1 6}, 442-443$.

GALE, E. F. (1946). The bacterial amino acid decarboxylases. Advances in Enzymology 6, I-32.

Gilboe, D. P., Friede, J. D. \& Henderson, L. M. (I968). Effect of hydroxylysine on the biosynthesis of lysine in Streptococcus faecalis. Journal of Bacteriology 95, 856-863.

Grandgenett, D. P. \& Stahly, D. P. (1971). Repression of diaminopimelate decarboxylase by L-lysine in different Bacillus species. Journal of Bacteriology 105, I 2 I I-I 2 I 2.

Kelleher, R. J. Jr \& HegGeness, M. (I976). Repression of diaminopimelic acid decarboxylase in Escherichia coli: gene dosage effects and escape synthesis. Journal of Bacteriology 125, 376-378.

LEIVE, L. \& DAVIS, B. D. (I965). The transport of diaminopimelate and cysteine in Escherichia coli. Journal of Biological Chemistry 240, 4362-4369. 
Lowry, O. H., Rosebrough, N. J., Farr, A. L. \& Randall, R. J. (1951). Protein measurement with the Folin phenol reagent. Journal of Biological Chemistry 193, 265-275.

Meadow, P., Hoare, D. S. \& Work, E. (1957). Interrelationships between lysine and $\alpha$, $\epsilon$-diaminopimelic acid and their derivatives and analogues in mutants of Escherichia coli. Biochemical Journal 66, 270-282.

Milner, H. W., LAWrence, N. S. \& French, C. S. (1950). Colloidal dispersion of chloroplast material. Science, New York III, 633-634.

Monod, J., Pappenheimer, A. M. \& Cohen-Bazire, G. (1952). La cinétique de la biosynthèse de la $\beta$-galactosidase chez Escherichia coli considérée comme fonction de la croissance. Biochimica et biophysica acta 9 , $648-660$.

Patte, J.-C., Loviny, T. \& Cohen, G. N. (1962). Répression de la décarboxylase de l'acide méso- $\alpha$, $\epsilon$-diaminopimélique par la L-lysine, chez Escherichia coli. Biochimica et biophysica acta 58, 359-360.

PAtTe, J.-C., Loviny, T. \& Cohen, G. N. (1965). Effets inhibiteurs cooperatifs de la L-lysine avec d'autres amino acids sur une aspartokinase de Escherichia coli. Biochimica et biophysica acta 99, 523-530.

PATTE, J.-C., Boy, E. \& Borne, F. (I974). Role of the lysine-sensitive aspartokinase III in the regulation of Dap-decarboxylase synthesis in Escherichia coli Kı 2. FEBS Letters 43, 67-70.

ROSNER, A. (1975). Control of lysine biosynthesis in Bacillus subtilis: inhibition of diaminopimelate decarboxylase by lysine. Journal of Bacteriology 121, 20-28.

SALEH, F. \& WhITE, P. J. (1975). Microbial methods for isolating the LL- or DD-isomer of 2,6-diaminopimelic acid. Proceedings of the Society for General Microbiology 3, 44-45.

SANwall, B. D. (1970). Allosteric controls of amphibolic pathways in bacteria. Bacteriological Reviews 34, 20-39.

Shimura, Y. \& Vogel, H. J. (1966). Diaminopimelate decarboxylase of Lemna perpusilla: partial purification and some properties. Biochimica et biophysica acta II8, 396-404.

Stewart, J. M. (196I). $\alpha, \epsilon$-Diamino- $\beta$-hydroxypimelic acid. II. Configuration of the isomers. Journal of the American Chemical Society 83, 435-439.

Truffa-BACHI, P. \& Cohen, G. N. (I970). Aspartokinase I and homoserine dehydrogenase I (Escherichia coli $\mathrm{KI}$ 2). Methods in Enzymology I7a, 694-699.

UMBarGer, H. E. (I969). Regulation of amino acid metabolism. Annual Review of Biochemistry 38, 323-370.

Vogel, H. J., Thompson, J. S. \& Shockman, G. D. (1970). Characteristic metabolic patterns of prokaryotes and eukaryotes. Symposia of the Society for General Microbiology 20, 107-1 19.

White, P. J. (I971). Diaminopimelate decarboxylase (Escherichia coli). Methods in Enzymology r7b, 140145.

WhITE, P. J. (1974). Prevention of lysine-repression of diaminopimelate decarboxylase by diaminopimelic acid. Proceedings of the Society for General Microbiology r, 72-73.

White, P. J. \& Kelly, B. (I965). Purification and properties of diaminopimelate decarboxylase from Escherichia coli. Biochemical Journal 96, 75-84.

White, P. J., Kelly, B., Suffling, A. \& WoRK, E. (1964). Variation of activity of bacterial diaminopimelate decarboxylase under different conditions of growth. Biochemical Journal 9r, 600-610.

White, P. J., Lejeune, B. \& WoRk, E. (1969). Assay and properties of diaminopimelate epimerase from Bacillus megaterium. Biochemical Journal 1r3, 589-601.

Work, E. (1957). Reaction of ninhydrin in acid solution with straight-chain amino acids containing two amino groups and its application to the estimation of $\alpha, \epsilon$-diaminopimelic acid. Biochemical Journal 67 , $416-423$.

WorK, E. (1962). Diaminopimelate decarboxylase. Methods in Enzymology 5, 864-870.

YUGARI, Y. \& Gilvarg, C. (1962). Coordinated end-product inhibition in lysine synthesis in Escherichia coli. Biochimica et biophysica acta 62, 612-6I4. 